\section{P156 OVERUSE OF INHALED CORTICOSTEROIDS IN ASTHMA PATIENTS WITH CONCURRENT EXERCISE-INDUCED LARYNGEAL OBSTRUCTION}

C Porsbjerg, A Sverrild, E Walsted, K Mirza. Respiratory Research Unit, Department of Respiratory Medicine, Copenhagen University Hospital Bispebjerg, Copenhagen, Denmark

\subsection{6/thoraxjnl-2015-207770.293}

Introduction Exercise induced laryngeal obstruction (EILO) causes asthma-like respiratory symptoms (i.e. shortness of breath and wheezing) and EILO is therefore difficult to distinguish from asthma in the clinic, resulting in a diagnostic dilemma in symptom based asthma management. We aimed to elucidate if the symptom contribution from EILO affected treatment strategy in patients suffering from both asthma and EILO compared with patients suffering from asthma only.

Methods We included 28 consecutively referred subjects with verified asthma, of which 11 had concurrent EILO. At baseline and at a one-year follow-up, all subjects underwent a thorough work-up consisting of a detailed clinical interview including asthma medication history, ACQ and mini-AQLQ scores, and diagnostic tests including spirometry, Mannitol and Methacholine bronchoprovocation tests, and fractional exhaled nitric oxide. Further, all subjects underwent a continuous laryngoscopy during exercise (CLE) test verifying the severity or absence of any concurrent EILO.

Results Subjects who suffered from both asthma and EILO were prescribed higher doses of inhaled corticosteroids (ICS) as a result of the baseline work-up $(\mathrm{P}=0.016)$ and were reduced in ICS doses at time of follow-up $(\mathrm{P}=0.027)$ and reported a significant decrease in ACQ-scores at one-year follow-up ( $\mathrm{P}=$ 0.016). In subjects with asthma only, there were no significant changes in ACQ scores at time of follow up despite of comparable asthma severities between groups at time of referral.

Conclusion EILO is a relevant differential diagnosis when managing patients with respiratory symptoms in a tertiary asthma clinic. Symptoms arising from EILO are difficult to distinguish from asthma symptoms, resulting in an ostensible overuse of ICS in patients with EILO. Further studies are needed to establish the clinical consequences and the optimal treatment strategy in this patient group.

\section{P157 INDIVIDUAL PATTERNS OF INHALER USE AND HEALTH OUTCOMES IN ADOLESCENTS WITH ASTHMA}

${ }^{1} \mathrm{~S}$ Howard, ${ }^{1} \mathrm{M}$ Patel, ${ }^{1} \mathrm{AR}$ Lang, ${ }^{2} \mathrm{C}$ Youle, ${ }^{2} \mathrm{H}$ Vyas, ${ }^{1} \mathrm{D}$ Shaw, ${ }^{1} \mathrm{~S}$ Sharples. ${ }^{1}$ University of Nottingham, Nottingham, Nottinghamshire; ${ }^{2}$ Queens Medical Centre Hospital, Nottingham, Nottinghamshire

10.1136/thoraxjnl-2015-207770.294
Background Electronic monitoring devices with an audio-visual reminder function can significantly improve asthma inhaler adherence and control in children. ${ }^{1}$ However, the relationship between attitudes, patterns of medication use and clinical outcomes are unknown.

Aim To examine individual patterns of inhaled corticosteroid use, and their relationships with clinical outcomes and qualitative feedback in adolescents with asthma.

Methods An exploratory study based on previous qualitative research investigating the attitudes of adolescents with asthma towards inhaler monitoring and data sharing. Patients from a specialist severe asthma clinic had their preventer inhaler use electronically monitored for one-month with a SmartTrack (Nexus6, Auckland, NZ) device. Adherence data was obtained and participants completed a questionnaire and interview at the beginning, middle and end of the trial on their attitudes. Ten months later, participants' case notes were examined for information related to their health before and after the study.

Results Spirometric data was captured on 4/7 participants and is presented alongside adherence data in Table 1 . Daily adherence ranged from 67\%-93\% with the largest FEV1 change $(+0.95)$ observed in P1 who had an average daily adherence of $73 \%$, and the smallest FEV1 change (-0.18) observed in P3 who had an average daily adherence of $93 \%$. All changes occurred without intensification of treatment. This fits with the previous qualitative findings that participants were enthusiastic about the reminders the SmartTrack device provided and felt more conscious of adhering to their treatment plan when they knew someone would be monitoring it. Participants spoke positively for utilising the data to demonstrate their adherence to their parents or doctor.

Conclusions Through examining inhaled corticosteroid use, attitudes and clinical outcomes we gain an understanding of each patient's condition including their habits with their inhaler (e.g. better adherence in the evenings), their attitudes to their asthma treatment and the potential effects of inhaler use on their health. Doing so helps us to identify patients who could benefit from intervention, to improve their inhaler taking behaviour and potentially improve their asthma control.

\section{REFERENCE}

1 Chan A, Stewart AW, Harrison J, et al. The effect of an electronic monitoring device (...). Respir Med. 2015;3:210-19

\section{P158 THE COST OF STEROID INDUCED MORBIDITY AMONG SEVERE ASTHMA PATIENTS IN THE UK}

${ }^{1} \mathrm{~L}$ Barry, ${ }^{2} \mathrm{~S}$ Sweeney, ${ }^{1} \mathrm{C}$ O'Neill, ${ }^{2} \mathrm{C}$ Patterson, ${ }^{3} \mathrm{D}$ Price, ${ }^{2} \mathrm{~L}$ Heaney. ${ }^{7}$ National University of Ireland, Galway, Ireland; ${ }^{2}$ Queens University of Belfast, Belfast, UK; ${ }^{3}$ University of Aberdeen, Aberdeen, UK

10.1136/thoraxjnl-2015-207770.295

Abstract P157 Table 1 Forced Expiratory Volume (FEV1) Spirometry values for four of the seven participants pre and post study

\begin{tabular}{|c|c|c|c|c|c|c|c|c|}
\hline & Pre Study & & Study Period & & & Post-Study & & \\
\hline Participant & $\begin{array}{l}\text { FEV1 } \\
\text { Value (L) }\end{array}$ & $\begin{array}{l}\text { Days Before Study } \\
\text { Start Date }\end{array}$ & $\begin{array}{l}\text { Daily Adherence } \\
\text { average (\%) mean }\end{array}$ & $\begin{array}{l}\text { AM Adherence } \\
\text { average (\%) mean }\end{array}$ & $\begin{array}{l}\text { PM Adherence } \\
\text { average (\%) mean }\end{array}$ & $\begin{array}{l}\text { FEV1 } \\
\text { Value (L) }\end{array}$ & $\begin{array}{l}\text { Change in FEV1 after } \\
\text { study participation }\end{array}$ & $\begin{array}{l}\text { Days After Study } \\
\text { End Date }\end{array}$ \\
\hline P1 & 2.15 & 28 & 73 & 71 & 76 & 3.1 & +0.95 & 372 \\
\hline P2 & 4.76 & 0 & 93 & 97 & 90 & 5.43 & +0.67 & 156 \\
\hline P3 & 2.86 & 23 & 93 & 94 & 92 & 2.68 & -0.18 & 69 \\
\hline P4 & 2.36 & 118 & 67 & 66 & 68 & 2.61 & +0.25 & 71 \\
\hline
\end{tabular}


Introduction Patients with severe asthma are estimated to comprise $5-10 \%$ of the total asthma population but contribute disproportionately to the overall burden of disease. A growing body of evidence exists that implicates steroid exposure in morbidity and healthcare costs among this group.

Aim This study sought to quantify the additional healthcare costs associated with steroid exposure among patients with severe asthma.

Methods Data on patients severe asthma (GINA treatment step 5 with $\geq 4$ prescriptions/year oral corticosteroids, $\mathrm{n}=808$ ), was obtained from the Optimum Patient Care Research Database (OPCRD) database along with age and gender matched mild/ moderate asthma patients (GINA treatment step 2/3, n = 3975) and non-asthmatic controls (rhinitis only, $\mathrm{n}=1865$ ) Data included details of all scheduled and unscheduled healthcare consultations and details of prescribed medicines. Data on service use were extracted for the two most recent years for which observations were available. Healthcare contacts were monetised using unit costs extracted from the Personal Social Services Research Unit's reference costs and for drugs using Prescription Cost Analysis data. All costs were expressed in their 2013 equivalents. Sensitivity analyses related to identification of staff providing specific consultations or activity, and high/low estimates based on assumptions used were produced. Mean high/low healthcare costs over two years by group were estimated and compared as were costs estimated separately for healthcare contacts and prescribed medicines.

Results As shown in Table 1 mean per patient drug, healthcare activity and combined drug and activity costs were significantly higher for the severe asthma group relative to the mild/moderate group with asthma and the non-asthma controls in both high and low cost scenarios. The mean difference in combined cost between the severe and non-asthma controls groups was between $£ 5,031$ (low cost) and $£ 5,545$ (high cost) depending on the cost scenario and $£ 4,098$ (low cost) and $£ 4,510$ (high cost) compared to the mild asthma group.

\begin{tabular}{|c|c|c|c|}
\hline \multirow{2}{*}{$\begin{array}{l}\text { Abstract P158 Table } 1 \\
\text { over } 2 \text { years }\end{array}$} & \multicolumn{3}{|c|}{ Mean (SD) per patient healthcare costs } \\
\hline & $\begin{array}{l}\text { Severe } \\
\text { asthma } \\
(n=808)\end{array}$ & $\begin{array}{l}\text { Mild/moderate } \\
\text { asthma } \\
(\mathrm{n}=3975)\end{array}$ & $\begin{array}{l}\text { Non-asthma } \\
\text { controls (rhinitis } \\
\text { only) } \\
(\mathrm{n}=1994)\end{array}$ \\
\hline Prescribed medicines (Mean) & $£ 3447$ & f972 & f514 \\
\hline (SD) & f5606 & f1619 & f1178 \\
\hline Activity- Low cost (Mean) & £4229 & $£ 2606$ & $£ 2131$ \\
\hline (SD) & f4296 & $£ 3267$ & $£ 2807$ \\
\hline Total - Low cost (Mean) & f7676 & $£ 3578$ & $£ 2645$ \\
\hline (SD) & f7490 & f3899 & £3254 \\
\hline Activity - High cost (Mean) & f5085 & f3051 & f2474 \\
\hline (SD) & f5364 & £4225 & f3529 \\
\hline Total - High cost (Mean) & f8533 & f4023 & f2988 \\
\hline (SD) & f8206 & f4791 & f3924 \\
\hline
\end{tabular}

Conclusions Patients with severe asthma matched by age and gender have significantly greater direct healthcare costs compared to patients with mild/moderate asthma and non-asthmatic subjects.

\section{P159 THE USE OF OMALIZUMAB IN SEVERE ASTHMA IS ASSOCIATED WITH A DECLINE IN BLOOD EOSINOPHILS}

${ }^{1} \mathrm{LJ}$ Holmes, ${ }^{2} \mathrm{G}$ Tavernier, ${ }^{2} \mathrm{~S}$ Fowler, ${ }^{1} \mathrm{~K}$ Hince, ${ }^{2} \mathrm{RM}$ Niven. ${ }^{1}$ University Hospital of South Manchester, Manchester, UK; ${ }^{2}$ Institute of Inflammation and Repair, Manchester Academic Health Sciences Centre, University of Manchester and National Institute of Health Research Respiratory and Allergy Clinical Research Facility, University Hospital of South Manchester, Manchester, UK

\subsection{6/thoraxjnl-2015-207770.296}

Introduction/aim Omalizumab (Xolair) is a recombinant humanised monoclonal antibody licensed for the treatment of severe allergic asthma patients with IgE mediated disease. The mechanism of action of omalizumab is to bind to IgE preventing interaction with FCERI (high affinity receptors) upon the surface of mast cells and basophils, thereby reducing the activation of the inflammatory cascade and associated clinical symptoms. Although blood eosinophilia is a useful measure of airway inflammation, the correlation between blood eosinophils and omalizumab treatment has not been described outside clinical trial. Therefore, our aims were to identify whether the introduction of omalizumab is associated with a change in the blood eosinophil count within our cohort of patients with severe asthma.

Methods We collected measurements of blood eosinophils in patients maintained on omalizumab for periods 12 months pre and post, and (where available) 24 months pre and post initiation of therapy. We also investigated any correlation between blood eosinophils pre and post treatment versus clinical parameters including total $\mathrm{IgE}$ and omalizumab dose.

Results Complete data sets including 12-month blood eosinophil data were available for 49 of our current cohort of 92 patients on treatment. The mean blood eosinophil count dropped from $0.33 \times 10^{9}$ cells $/ 1($ IQR 0.37$) \times 10^{9}$ cells/l pre-treatment to 0.22 $\times 10^{9}$ cells/l (IQR 0.30$)$ post treatment $(p=<0.001)$.

Additionally, we widened the window to 24 months pre and post initiation of treatment, if blood eosinophil data was not available at 12 months. Data for 59 patients demonstrated similar significant reduction in mean blood eosinophil, $0.34 \times$ $10^{9} \mathrm{cells} / \mathrm{l}$ (IQR 0.34$)$ pre-treatment to $0.23 \times 10^{9}$ cells/l (IQR $0.29)(p=0.003)$.

No association was seen between the changes in mean blood eosinophil counts post treatment versus total monthly omalizumab dose and baseline total IgE.

Conclusion Our data demonstrates a significant reduction in blood eosinophils in patients who are receiving omalizumab treatment when comparing blood eosinophils at 12 and 24 months pre and post treatment. Future work should investigate whether this is a direct result of omalizumab therapy, due to confounding by other treatment, or a marker of improved asthma control.

\section{P160 BONE PROTECTION IN ORAL CORTICOSTEROID DEPENDANT ASTHMATICS}

HH Hashim, PL Molyneaux, S Regan, JH Hull, A Menzies-Gow. Royal Brompton Hospital, London, UK

\subsection{6/thoraxjnl-2015-207770.297}

Introduction Asthmatics dependant on oral corticosteroids are at risk of bone loss and significant increase in fracture risk at the hip and spine. Current guidelines recommend assessment of bone mineral density and the need for bone protection in any patient exposed to glucocorticoids for over three months. We 